\title{
NOTAS (FILOSÕFICAS) SOBRE O PROBLEMA DA FORMAÇÃO DE PROFESSORES
}

\author{
Rodrigo Pelloso Gelamo_(1) \\ Márcia Machado de Lima_(2)
}

Resumo: Rompemos com a análise que tem como paradigma a universalidade e a cientificidade na busca por respostas para a formação de professores.

Problematizamos a idéia da formação de professores como resposta ao problema da crise na/da escola e o uso de conceitos no discurso educacional. Relacionamos os pontos problematizados, vistos como inerentes à prática educadora, com a constituição e validação do costume. O costume como crença arraigada quanto à existência do Homem pronto, finalidade da formação no universo da prática educacional. Entendemos que o tema formação de professores não se submete à objetivação de uma compreensão por um sujeito do conhecimento, ou mesmo, a um estudo analítico da verdade a seu respeito. Sugerimos como produtiva a busca de estilo foucaultiano de uma ontologia do presente acerca do problema da produção de formadores.

Lugares comuns. Idéias consagradas. Problemáticas crônicas, talvez insolúveis. Discussões recorrentes. Poderíamos aplicar tudo isto ao tema "formação dos educadores". Esta questão permanece na ordem do dia segundo o olhar acadêmico à questão. A recorrência fornece indicadores de que tal tema pertence ao rol daquilo que deve ser tratado de forma mais detida.

É só abrir os jornais ou acompanhar o noticiário da TV (3), além das próprias publicações do meio educacional. Com muita freqüencia, num volume que salta aos olhos, fatos entre si diversos, ligados à educação são informados e analisados por experts e por outras pessoas que se declaram defensores do direito $e$ da cidadania e preocupados com a formação dos educadores.

A mídia, neste caso, fornece-nos um dos índices: o poder de mobilização que esta questão possui. Educação é notícia! Mais do que isto. A educação se constituiu em uma problemática que afeta os dias que correm e é tratada como um problema crônico.

Certa urgência em apresentar respostas ao problema da formação de professores é um dado flagrante, também indicado em mídias especializadas, assumido como parte da crise do ensino. Traço que marca esta produção é a necessidade apresentada pelas pesquisas na área em estabelecer questões, projetos, políticas, enfim, respostas para aquilo que se convencionou chamar de "crise do ensino".

Esta crise nos move na busca incessante de encontrar a resposta ao problema da crise do ensino. 
Esse preconceito é social (pois a sociedade, e a linguagem que dela transmite as palavras de ordem, "dão"-nos problemas totalmente feitos, como que saídos de "cartões administrativos da cidade", e nos obrigam a "resolvê-los", deixando-nos uma delgada margem de liberdade). Mais ainda, o preconceito é quase infantil e escolar, pois o professor é quem "dá" os problemas, cabendo aos alunos a tarefa de descobrir-lhes a solução. Desse modo, somos mantidos numa espécie de escravidão. (Deleuze, 1999, p.09).

No centro da discussão está o professor. Há uma pluralidade de discursos que cercam esta figura, dada a instância na qual circula, muito próxima do espaço de relações na teia das quais o conhecimento é produzido, principalmente quando se trata da produção no interior da escola, no/do espaço da docência. Discursos acerca do professor e da formação de professores acontecem em sentidos que formam um campo diversificado, no qual convivem planos distintos.

Percebemos discussões por vezes insólitas. Outras vezes, ordenadas, controladas e esperançosamente propositivas. E em alguns momentos, discussões acontecem a partir do lugar do não-compreensível - como tudo o que nos dá o que pensar.

No que respeita a produtividade do lugar do não-compreensível, dizem Larrosa \& Skliar (2001).

A nossa questão não é a nostalgia nem a esperança, mas a perplexidade. E é o Presente o que nos é dado como incompreensível e, ao mesmo tempo, como aquilo que nos dá o que pensar. Por isso, ao nosso tempo, [...] um tom épico, de luta e de entusiasmo, no qual caberia a conquista do que seremos e, entretanto, não conseguimos ser; nem tampouco um tom clássico, de ordem e estabilidade, no qual caberia o repouso satisfeito do que somos. O nosso não é o lamento nem a serenidade, mas o desconcerto. Por isso o nosso é, melhor dizendo um tom caótico no qual o incompreensível do que somos se nos mostra disperso e confuso, desordenado, desafinado, em um murmúrio desconcertado e desconcertante, feito de dissonâncias, de fragmentos, de descontinuidades, de silêncios, de casualidades, de ruídos. (p.08).

Formação de professores não é um tema simples. Isto nos levou a tentar organizar este texto como um registro do problema que apenas começa a se colocar para nós. A partir daqui não entendemos mais o problema como sinônimo de questões ou de perguntas, mas problema como aquilo que ataca o pensamento. Essa atitude está fundamentada na proposta deleuziana que afirma que "A verdadeira liberdade está em um poder de decisão, de constituição dos próprios problemas: esse poder, "semidivino", implica tanto no esvaziamento de falsos problemas quanto no surgimento criador de verdadeiros" (Deleuze, 1999, p.09).

O caráter ontológico da questão impõe que continuemos a nos perguntar acerca de como a formação de professores se constitui como problema. Mas em um sentido diferente daquele da busca por respostas já estabelecidas que poderiam ser adaptadas para as circunstâncias requeridas às questões levantadas. Nesse sentido, é necessário manter a formação dos professores como um problema: tenso. O que 
pretendemos é justamente romper com a análise que tem o paradigma da universalidade e da cientificidade que trilha caminhos insólitos na busca de uma padronização do ensino.

Queremos problematizar a formação de professores a partir de uma ontologia do presente, ao modo foucaultiano de proceder. Para Foucault (1994), é Kant quem primeiro propõe este método de análise que leva em conta o tempo presente.

Segundo o autor,

[...] existe na filosofia moderna e contemporânea um outro tipo de questão, um outro modo de interrogação crítica: é esta que se viu nascer justamente na questão da Aufklärung ou no texto sobre a revolução; 'o que é nossa atualidade? Qual é o campo atual das experiências possíveis?'. Não se trata da analítica da verdade, consistiria em algo que se poderia chamar de analítica do presente, uma ontologia de nós mesmos [...] (p. 188).

Foucault faz funcionar esta questão kantiana de um modo próprio, potencializando o pensar sobre o tempo presente. Esta relação demarca a perspectiva que nos move a levantar a seguinte questão: o que estamos fazendo enquanto educadores? $\mathrm{Ou}$, para manter a questão num âmbito mais geral, o que temos encontrado atualmente no plano instituído da discussão no campo educacional acerca da formação de professores? Ou, ainda, como devemos proceder diante de tais problemas?

1. Há posições que circulam e, de alguma maneira, disputam. Algumas se tornaram majoritárias (4).

Há os técnicos para os quais a "crise do ensino" reflete a falta generalizada de capacitação por parte dos educadores quanto ao manuseio dos instrumentos pedagógicos que otimizariam o tempo e a produção na busca de respostas e resultados.

Para Larrosa (2002),

Atualmente, o conhecimento é essencialmente a ciência e a tecnologia, algo essencialmente infinito, que só pode crescer; algo universal e objetivo, de alguma forma impessoal; algo que está aí, fora de nós, como algo do qual podemos nos apropriar e utilizar; e algo que tem a ver fundamentalmente com o útil no seu sentido mais estreitamente pragmático, com a fabricação de instrumentos. (p.140).

Além disso, tal sentido da capacitação, segundo o autor, dirige-se à busca por um saber eficaz que produza resultados imediatos. Larrosa se refere aos:

[...] que se situán en el campo educativo desde la legitimidad de la ciência, los que usan esse vocabulário de la eficácia, la evaluación, la calidad, los objetivos, los didactas, los psicopedagogos, los tecnólogos, los que construyen su legitimidad a partir de su cualidad de expertos, los que saben, los que se situán en posiciones de poder a través de posiciones de saber [...]. (Larrosa, mimeo). 
O saber técnico científico constituir-se-ia, então, no aval à valoração como boa à acumulação de conhecimentos bem classificados, constituindo a "bagagem" profissional. A consolidação de tal "bagagem" garantiria, portanto, a quem a detém, todas as condições técnicas de responder às situações adversas que o campo profissional colocaria ao professor cotidianamente. Tal capacitação implica ainda as idéias, em última instância, de universalidade, objetividade e aquisição definitiva na relação com o conhecimento.

Para os críticos, por sua vez, caberia aos educadores a tarefa de viabilizar concretamente os projetos, os processos e as políticas que têm como fim assegurar que a escola cumpra seu papel social e sua missão: ensinar e ensinar bem. Seguramente, deste modo, estaria promovendo a concretização das expectativas acerca da sociedade justa, cidadã, o objetivo, este sim, legítimo.

Tanto na perspectiva dos técnicos quanto na dos críticos, é recorrente a produção acadêmica sobre formação de professores. A pretensão maior é de que o terreno possa ser remexido, a terra possa ser revolvida, que a discussão possa ser retomada. Pretendem ensinar para uma finalidade, para um objeto fim. Para isso criam métodos para alcançar este objetivo.

O problema da finalidade da educação aparece em ambos os casos. Ambos têm como paradigma o ideal de Educação como meio para se alcançar a perfeição. Tanto em um caso quanto noutro, o ensinar é sempre um caminho universal e necessário. Este ponto os une no mesmo paradigma de racionalidade.

A formação de educadores entendida a partir da cultura e ao nível da prática impõe, também, um caminho universal e necessário. A necessidade determina os padrões de comportamento e de moralidade aos educadores, restringindo seu fazer educacional a uma reprodução de práticas e de métodos entendidos como os melhores meios de transmissão de conhecimento.

No âmbito da filosofia moral, o costume é o formador do senso e da consciência do sujeito instituindo um compromisso moral dele para com determinadas atitudes em relação ao Bem, e não outras, as quais fazem parte de suas crenças e que o impelem no caminho considerado acertado. Esta é uma discussão que afeta diretamente o educador em todas as suas instâncias - profissional, familiar, política, ou seja, em todos os contextos em que está inserido cotidianamente. Isto especialmente porque o universo da produção do conhecimento que o envolve, mesmo sendo múltiplo, nele está implicado um movimento ideológico, de fechamento, que impõe parâmetros para a validação, independente da forma e do grau de sua consciência, de seu senso moral, quanto ao que está implicado. Recorrendo à unidade representacional: a moral. Segundo Gallo (2004), "A função ideológica da escola não é, porém, necessariamente inerente a ela; percebemos que na história social da dominação do homem sobre o homem, a escola tem servido de suporte, como um dos aparelhos ideológicos [...]".

Esta dimensão sub-reptícia envolve mais que a dimensão formal da formação, demarca fronteiras dentre as quais a sua discussão acontece. Se isso nos bastasse, 
ainda estaríamos crendo em uma Verdade Moral. Sentimentos, condutas, ações formam um tecido intrincado a partir da produção de subjetividade nas instâncias das quais participam. Acredita-se que a participação social, entendida como a formação, apesar e porque se trata de trajetória vivida, forma-os como a quaisquer outros agentes, segundo o ethos - o costume. É importante justificar que, ao dizer ethos, estamos nos referindo aqui ao conjunto de costumes tradicionais de uma sociedade, que devem ser coletivizados, assumidos por todos e considerados valores e obrigações para a conduta de todos. Em outras palavras, cada um apreende o ethos visto como costume, que por ser anterior ao aparecimento do agente e por formar o que distingue a sociedade na qual vive, deve ser incorporado em bloco pelo senso moral de cada indivíduo e defendido com consciência crítica.

Em O Existencialismo é um Humanismo, Sartre explica que existem três instâncias que afastam o homem de sua consciência livre. Uma delas é a moral. A crença na existência da moral determina o processo de escolha do homem. A mesma crença na moralidade cria no homem a má-consciência, nas palavras de Sartre, a má-fé. Gallo (2004), trazendo a proposta sartreana à discussão afirma que

É nesse momento que ganha a cena o fenômeno da má-fé. O indivíduo lança-se ao teatro, à representação de papeis na busca de sua identidade, de seu reconhecimento e de sua apresentação ao mundo como um isso e não como um nada. A má-fé é a forma de preencher o vazio de ser da subjetividade. Como será minha ação na sociedade, como agirei sob o olhar inquiridor do outro?

Nesse sentido,

[...] a função da ideologia da escola não é apenas e tão somente a de mascarar ou mesmo justificar a realidade social da dominação. Muito mais do que isso, a função ideológica da escola é a de fornecer um referencial externo para o desenvolvimento das estruturas subjetivas de cada indivíduo, cooptando-o para o reino da máquina de produção social. (Gallo, 2004).

Esta reflexão sobre o conceito de costume acaba dando visibilidade para um ponto comum, qual seja, a busca da Verdade que permeia o campo educacional. Parte dessa tarefa cabe à instituição escolar e está colocada para os educadores, podendo ser constatada nos documentos de planejamento de ensino e nos projetos político-pedagógicos. Tanto para os grupos de educadores críticos como para os grupos de educadores técnicos, guardadas as devidas diferenças de posicionamento, a formação do sujeito ético - de caráter, consciente, que não se submete aos acasos da vontade e aos desejos de um outro, mas obedece apenas à sua consciência com autonomia e à sua vontade racional porque reconhece o Bem $e$ as Virtudes - é objetivo a ser alcançado. Voltamos a dizer, estamos entretecidos nestes lugares, na trama do campo no qual estas relações se dão e nos envolvem.

Esta concepção, como um marco da modernidade, mostra que o Homem tenta escapar à sua condição de parte integrante da Natureza, construindo racionalmente ascendência e descendência fora dela, tornando-a um reino independente da 
cultura. A preocupação a partir deste marco é definir em que momento e quais são as maneiras pelas quais se faz o mundo cultural - instituído como genuinamente humano - surgir. Esta perspectiva, clássica, indica o surgimento da lei, humana, que não pode ser transgredida, não ao menos a um preço menor que a ruína da comunidade e do indivíduo. Esta lei funciona como um imperativo social que organiza a vida, determinando a constituição do costume e dos meios de transmissão.

1. A lei do dever seré a afirmação da separação do humano de seu aspecto natural, a afirmação de que é capaz de criar uma ordem de existência simbólica, ou seja, de significações a serem atribuídas à realidade e que mediarão a relação do Homem com o mundo. Dito de outra forma, o homem cria a formulação de representações da realidade.

Este é o paradigma clássico de cultura que tem como orientação primordial que o espírito humano e a sociedade humana, por serem singulares na natureza, devem encontrar sua auto-compreensão, sua inteligibilidade, prioritariamente na antítese a um universo biológico sem espírito e sem sociedade. A definição clássica de Homem é dada, portanto, em oposição ao animal; a da Cultura por oposição à Natureza; aquela da racionalidade humana organizada em oposição aos mecanismos considerados instintivos naturais. Este pensamento mantém-se encerrando o Homem em uma concepção insular, dicotômica.

A tarefa, portanto, é colocada no sentido da dominação, da sujeição, da conquista, da afirmação construída da superioridade do sapiens. Kohan (2003) comentando Foucault afirma que

O poder é algo diferente da dominação embora existam entre eles algumas semelhanças (igual ao poder, a dominação é algo que se exerce, e também não existe em singular: na sociedade capitalista não há uma dominação global, mas múltiplas dominações), a uma diferença profunda em termos de liberdade. A dominação se exerce num Estado onde as relações de poder estão fixas, assimétricas, e onde não há mais do que uma limitadíssima liberdade. O poder se exerce para determinar a conduta de outro, mas nunca de forma exaustiva ou coercitiva. (p.89).

Tal proposição faz com que o Homem subjulgue seu semelhante na luta pelo poder, pela posição legítima e valorizada no grupo, herdada, como característica inerente à prática.

Os séculos de educação institucionalizada construíram a tendência clássica que espera do homem que esteja pronto quando adentra aos portões escolares. $\mathrm{O}$ historiador Philippe Ariès (1981) afirma que a escola se institucionaliza a partir do século XV. Até então era entendida apenas como um asilo para crianças pobres e abandonadas. Segundo Kohan (2003), nessa escola

[...] os indivíduos não fazem qualquer coisa, em qualquer momento, em qualquer lugar. Os espaços são cuidadosamente delimitados, o tempo é marcado por um 
cronograma preciso, regular e regulado, os aprendizados são organizados em etapas, de forma tal a exercitar em cada período um tipo de habilidade específica. Um conjunto de formas reguladas de comunicação (lições, questionários, ordens, exortações, sinais codificados de obediência) e um conjunto de práticas de poder (clausuramento, vigilância, recompensas e punição, hierarquia piramidal, exame) conformam o campo do que é possível perceber, dizer, julgar pensar e fazer na instituição escolar (p.79).

A este Homem pronto, já formado em sua essência, a escola transmitiria o conhecimento também clássico, parte do patrimônio cultural universal, próprio do humano. Essa concepção tornou-se, ao longo do processo histórico de constituição da educação, crença arraigada, naturalizada sobre a qual é perda de tempo pensar. Tal crença permeia o discurso não só dos grupos de educadores tradicionais que defendem o cultivo do espírito como fundamento da educação, mas também é possível perceber esta marca no discurso dos grupos de educadores que, constituindo-se em certo senso caracterizador, tem como fundamento da educação a formação do cidadão.

O que fizemos até aqui? Tratamos em um primeiro momento o que concerne ao modo como vem sendo tratada a formação de professores como aspecto fortemente relacionado ao problema da crise na escola - questão, a nosso ver, definidora da pesquisa acadêmica e da ação da escola.

Em um segundo momento, problematizamos o uso de conceitos no discurso educacional. Talvez seja importante acrescentar ao dito anteriormente que as produções especializadas do campo educacional, fazem circular diferentes acepções de formação: capacitação, reciclagem, treinamento, profissionalização docente. Muito do que circula, contudo, não mostra a preocupação com o lugar de onde se está falando, qual o conceito de formação que está sendo utilizado. Fazendo com que o conceito se torne esvaziado.

Em um terceiro momento, caracterizamos as relações destes elementos inerentes à prática educadora com a constituição e validação de costume que imprime crença arraigada quanto ao homem pronto no universo da prática educacional, seja quando o objetivo é a formação do cidadão, seja quando é o cultivo do espírito, que tem como característica fundamental a dualidade entre o Homem e suas relações, sejam elas quais forem.

Estes são os aspectos com os quais nos encontramos quando pensamos a formação de professores. Tentaremos trabalhar a partir de uma posição diferente daquela referida comumente à constituição de sujeitos educadores como um princípio universalmente aceito. Para Veiga-Neto (2004) as

Noções como o "eu pensante" de Descartes, a "mônada" de Leibniz, o "sujeito do conhecimento" de Kant foram fundamentais para que se firmasse a idéia de que o sujeito é uma entidade já dada, uma propriedade da condição humana e, por isso, desde sempre aí, presente no mundo. A própria noção moderna que o sujeito é a matéria-prima a ser trabalhada pela Educação - seja para levá-lo de um estado 
selvagem para o estado civilizado (como pensou Rousseau), seja para levá-lo da menoridade para a maioridade (como pensaram Kant Hegel e Marx) - partiu do entendimento de que o sujeito é uma entidade natural e, assim, pré-existente ao mundo social, político, cultural e econômico. (p.132).

Quando focado nas relações e no próprio movimento do processo no campo de produção, buscando a proximidade com os agentes, o olhar se dá conta de inúmeros pontos de visão, nuances, posicionamentos, sentidos comuns, fluxos insistentes e descontínuos que, mesmo parte do que nos constitui, lugar onde nos movimentamos, não se dão em aparência. Servem também como motivadores e reproduzem as práticas educacionais cristalizadas em modelos de ensino e de pensamento.

Dado o grau da contribuição da instituição escolar para a legitimação e naturalização das relações que instituem a dominação, é na mesma medida importante, talvez crucial, manter o questionamento acerca da formação do educador como problema.

Acreditamos ser pertinente criticar a base conceitual que move a sociedade para crer nestes mitos de estratificação por ela criados e, tradicional e sub-repticiamente, herdados. Acreditamos que uma intenção profícua seja problematizar o mito que propõe uma Verdade para o Bem e para o Malna ação social, seja dos grupos conservadores (uma face da moeda) seja dos grupos ditos de esquerda (outra face da moeda). Isto se mostra pertinente, visto que estamos problematizando o método utilizado por essas vertentes, a saber: o da analítica da verdade que tem em seu fundamento verdades pré-estabelecidas, verdades transcendentais, que serviriam como um a priori que determinaria o conhecimento - ou o que é legítimo conhecer -, ou seja, para analisar e se posicionar segundo parâmetros de ordem ou controle marcados pelas idéias sociais dominantes.

O professor é figura fundamental nesta discussão, que permeia todo o movimento de sua formação. Isto porque agencia para si a relação mais próxima de singularidades que tem o poder de ou perpetuar o costume, governando o outro em sua relação com o aluno, ou na mesma medida e pelo mesmo motivo, aproveitando as brechas, tornar-se elemento fundamental para a colocação do costume em xeque.

Olhar além do aparente. Talvez esta intenção, a insistência neste ponto, possa problematizar o fechamento da discussão sobre formação de professores. Entrar na lógica do sentido e não da formalidade na qual os discursos majoritários são desenvolvidos e funcionam para produzir o conceito tradicional de sistema educacional como único caminho de formação. Lógica fluida e imanente, encarregada de dar sustentação à transmissão da cultura legítima como herança. Para isso, temos que colocar o problema na ordem do acontecimento, fazer uma ontologia do presente. Não nos restringindo à ordem do dever ser reificado na estrutura de uma teleologia educacional, que tem como fim a Verdade. Entrar na espessura da realidade. 
Neste sentido, acreditamos que o paradigma tradicional da racionalidade, que funda o modo dominante de pensar a formação de professores, legitimou um modo de entender que o que é digno de ser pesquisado são as questões historicamente colocadas. Ao lado disso, e fortemente, os métodos de pesquisa para o entendimento destas questões também devem ser os da Ciência, Filosofia, História etc, já consagrados e cuja utilização esteja na moda como meio de entendimento da realidade. Neste caso, a formação de professores.

Este mecanismo determina, em contrapartida, que coisas que poderiam desencadear outras também muito produtivas de se dizer, fazer e pesquisar não sejam ditas, feitas e pesquisadas. Determina ainda que temas, não menos dignos de interesse, não afetem à maioria das pessoas, somente podendo ser tratados de modo que fique bem claro que fazem parte de um escalão de coisas menos valorizado, por estar fora das "verdadeiras preocupações contemporâneas". No entanto, estes discursos menos poderosos circulam ao lado dos outros.

O modo como vem sendo tratada esta questão/problema, de qualquer forma, aponta para a necessidade do trato cuidadoso. Apesar de todo o movimento do campo educacional, permanece a "crise do ensino" como um quadro cristalizado. Formação de professores é, sem dúvida, um dos temas mais debatidos - e este ponto nos salta aos olhos. A recorrência continua, mas a redundância não faz avançar. Talvez possamos agregar a este quadro outro elemento: a ausência do espanto. Tornou-se lugar comum, por exemplo, ouvir com tranqüilidade que a escola pública é de péssima qualidade e isto ser tomado como verdadeiro, legítimo e natural.

Manteremos-nos no lugar do não-compreensível. Isto porque

[...] O que se quer, ao compreender, é converter [...] o estranho em familiar [...]. Aquilo que ele compreende o faz melhor: mais culto, mais sensível, mais inteligente, mais rico, mais cheio, maior, mais alto, mais maduro. Talvez por isso, ele compreende tudo a partir de sua riqueza, a partir de sua plenitude, a partir de sua grandeza, a partir de sua altura, a partir de sua maturidade. Por isso, o sujeito da compreensão é o tradutor etnocêntrico: não o que nega a diferença, mas aquele que se apropria da diferença traduzindo-a à sua própria linguagem. (Larrosa; Skiar, 2001, p. 19).

Concordamos que o debate deva ser feito. Mas talvez uma pergunta deva ser colocada aqui: como? Parece-nos que as questões são repetidas e repetidas e repetidas ... É como se se acreditasse em uma definição dominante das coisas boas de se dizer e de temas que mereçam ser alvo de interesse, enquanto outros não o são. Talvez o debate esteja apenas sendo recorrente a pseudo-problemas, porque não produz os problemas, não os inventa. Como pretendem Deleuze e Guattari

Devemos inventar um problema no sentido de não buscar simplesmente um problema que já foi anteriormente colocado à moda dos pseudo-problemas, que não correspondem ao movimento de produção de realidade. $\mathrm{O}$ movimento de produção instala problemas na realidade, e o conceito é a resolução dos 
problemas. Os pseudo-problemas são formulados de maneira tal que o ato de postulá-los já é uma tentativa de formulação-problema relacionada a uma resposta já elaborada e sabida. Em outras palavras, os pseudo-problemas são postulados de tal forma a adequar os significados a significantes universais, a respostas já conhecidas (Gelamo, 2003, p.11-12)

Estamos todos enterrados nestes lugares comuns. Tais relações estão entranhadas em nós professores e, muitas vezes, pesquisadores, entretecidos que estamos na trama do próprio campo, na realidade educacional.

A pesquisa educacional tem produzido em grande volume a discussão sobre a formação dos professores. O tratamento dado ao conceito coloca-o à beira do desgaste pelo uso excessivo e vulgarizado. Muitas vezes passa a fazer parte de discursos prontos, em cujos textos a tensão produtiva se perdeu, dando lugar à reiteração. Exatamente por esse motivo, para nós, ainda se faz necessário mantê-lo como problema. No entanto, estamos tentando constituir um plano em um sentido que não o enrijeça, o cristalize e o torne, de novo, parte de mais um texto pronto. Que, assim, permita a insistência: como manter a formação de professores um problema?

Não queremos simplesmente tecer questões e, quem sabe, nos surpreender com respostas, mantendo-nos apenas na recorrência sobre temas e métodos. Queremos problematizar as relações referentes a uma instância fundamental, micropolítica, lugar no qual se produz o problema da "formação de educadores". Fazer a ontologia do presente proposta por Kant e desenvolvida por Nietzsche e Foucault, como problematização do próprio tempo presente. Segundo Veiga-Neto (2004), a proposta está formulada do seguinte modo:

A ontologia do presente é uma ontologia crítica de nós mesmos; ela desloca a questão (kantiana) [quem somos nós? uma variante da pergunta que é isso?] para uma outra questão, também já presente em Kant, porém enfatizada por Nietzsche e que pode ser formulada da seguinte maneira: "que se passa com nós mesmos?". Essa nova pergunta põe em relevo o sentido e o valor das coisas que acontecem conosco no nosso presente, não mais perguntando sobre as condições necessárias para determinar a verdade das coisas [...] (p.46).

Isso é o que chamamos de insistência.

Entendemos que o tema não se submete, assim, a uma objetivação de uma compreensão por um sujeito do conhecimento, ou mesmo a um estudo de estilo analítico da verdade a seu respeito, mas numa busca ao modo nietzschiano/foucaultiano de uma genealogia na formação de professores.

\section{Referências}

ARIÈS, P. História social da infância e da familia. Rio de Janeiro: LTC, 1981.

DELEUZE, G. Conversaçôes. Rio de Janeiro: 34, 1992. 232p. 
DELEUZE, G. Diferença e Repetição. Rio de janeiro: Graal. 1998, 499p.

DELEUZE, G. Bergsonismo. São Paulo: 34, 1999, 139p.

DELEUZE, G. GUATTARI, F. O Que é a Filosofia? Rio de Janeiro: 34, 1992. 288p.

FOUCAULT, M. A ordem do discurso. 2.ed. São Paulo: Loyola, 1996. 79p.

FOUCAULT, M. Dits et Écrits. Paris: Gallimard, 1994, vol. IV, pp. 679-688.

GALLO, S. D. Educação, ideologia e a construção do sujeito. In:

www.educacaoonline.pro.br/educacao_ideologia.asp?f_id_artigo=183. acessado em: 10/11/2004.

GELAMO, R. P. Enunciação sem sujeito. 2003. 82 f. Dissertação de mestrado. Faculdade de Filosofia e Ciências, Universidade Estadual Paulista, Marília, 2003.

KOHAN, W.O. Infância: entre a educação e a filosofia. Belo Horizonte: Autêntica, 2003. 283p.

LARROSA, J; SKLIAR,C. Babilônios somos. A modo de apresentação. In: (org). Habitantes de Babel; políticas e poéticas da diferença. Belo Horizonte: Autêntica. 2001.p.7-30.

LARROSA, J. La Experiencia y sus lenguajes. Conferência proferida no Seminário "La Formación Docente entre el siglo XIX el siglo XXI". acessado em: 1710/2004.

LINS, D. et al. Cultura e subjetividade: saberes nômades. Campinas: Papirus. 1997. p. 115

NIETZSCHE, F. Obras Incompletas. São Paulo: Abril Cultural, 1983. 416p. (Col. Pensadores).

VEIGA-NETO, A. Foucault e a educação. 2.ed. Belo Horizonte: Autêntica, 2004. $191 p$.

(1) Mestre em Filosofia e Doutorando em Educação pela Universidade Estadual Paulista (UNESP) Campus de Marília. Prof. da Faculdade de Ciências e Tecnologia de Birigui (FATEB).gelamo@feteb.br

(2) Mestre e Doutoranda em Educação pela Universidade Estadual Paulista (UNESP) Campus de Marília.mmachado@fateb.br

(3) Em novembro de 2004, o Fantástico (revista dominical da TV Globo) mostrou uma reportagem feita a partir de dados apresentados pelo Instituto Nacional de 
Pesquisas Educacionais Anísio Teixeira (INEP) quanto às habilidades de leitura dos alunos ao final da quarta série, indicando o baixo índice da capacidade na leitura, compreensão e interpretação de textos escritos. Não obstante, o olhar da mídia procurou ressaltar o que era de seu interesse para que o tema virasse notícia. Desse modo, indicaram que o problema da educação poderia estar na escola e, principalmente, na formação dos educadores responsáveis diretos pelo processo.

(4) Para Foucault, "[...] o discurso está na ordem das leis; que há muito tempo se cuida de sua aparição; que lhe foi preparado um lugar que o honra mas o desarma; e que, se lhe ocorre ter algum poder, é de nós, que ele lhe advém". E pergunta "o que há, enfim, de tão perigoso no fato de as pessoas falarem e de seus discursos proliferarem indefinidamente? Onde, afinal, está o perigo?" para, então, enunciar a sua hipótese: "suponho que em toda a sociedade a produção do discurso é ao mesmo, controlada, selecionada, organizada e redistribuída por certo número de procedimentos que têm por função conjurar seus poderes e perigos, dominar seu acontecimento aleatório, esquivar sua pesada e temível materialidade" (1996, p.7-9) 